\title{
Rules of the Road: Compliance and Defiance among the Different Types of Cyclists
}

Transportation Research Record 2019, Vol. 2673(9) 34-43

(C) National Academy of Sciences: Transportation Research Board 2019 Article reuse guidelines: sagepub.com/journals-permissions DOI: $10.1177 / 036 \mid 198119844965$ journals.sagepub.com/home/trr (SSAGE

\author{
Nick Chaloux' and Ahmed El-Geneidy'
}

\begin{abstract}
Although cycling has become a more attractive option to commuters in many North American cities recently, significant apprehension remains around its safety. Though risks experienced by cyclists are diverse, the idea that they are because of scofflaw cyclists-cyclists who regularly ignore the rules of the road-remains prevalent. Improving cycling safety requires countering this idea, and therefore an understanding of how different cyclists act under the existing rules. Using a survey of I,329 cyclists in Montreal, Canada, this study generated a typology of cyclists based on cycling motivations and behaviors and conducted comparisons based on their responses to four cycling rule-breaking scenarios. Our study shows that all cyclist types contravene traffic laws in similar ways, and $0.6 \%$ of respondents consistently follow the traffic laws. Breaking the law was often considered the safest option by respondents, which reflects a disconnect between the safety goals of traffic laws and the reality on the streets based on the perspectives of different cyclist types. Although cyclist types may act similarly in response to existing laws, they still respond uniquely to policies aimed at increasing rule adherence. Targeted interventions aimed at educating young cyclists, improving dedicated infrastructure, and prioritizing cycling traffic could increase rule compliance across all types. Through our study, planners, policy makers, and law enforcement could improve cycling safety by better understanding the behavior and rationale taken by cyclists.
\end{abstract}

Cycling has grown as a viable commuting option in many North American cities recently, becoming a competitive way to get around urban areas for many users. However, collisions with motorists remain common for cyclists, with injuries and fatalities receiving significant media attention recently in cities like Toronto and Montreal ( 1 , 2). Despite these collisions often being to no fault of the cyclist, public perception of cyclists remains antagonistic. Cyclists are perceived as rule-breakers, receiving the blame for conflict on the streets in the public's perception (3). Efforts to increase cycling safety often encounter opposition attributable in part to this characterization.

Countering the rule-breaking perception of cyclists requires an understanding of different cyclists' rulebreaking behaviors. Though many typologies of cyclists have been generated, none as yet have included risktaking in their classification. Rule-breaking and risktaking in cycling literature has largely focused on explaining why some cyclists run red lights $(4,5)$, though one major study aims at answering who the rule-breakers are (6). Building on the existing literature, this study generated a unique typology that includes risk-taking behaviors, derived from a 2018 survey of 1,329 cyclists in
Montreal, Canada. Through comparison of their responses to four rule-breaking scenarios, we evaluated each cyclist type's responses to better understand why some do not follow the rules. Four targeted approaches based on the unique identities of each cyclist type are proposed, meant to accompany revisions to existing traffic laws. These interventions affect the types differently, but all serve to increase rule compliance amongst cyclists.

This article commences with a review of the existing literature about cyclist typologies; prior research on risktaking and rule-breaking by cyclists is then discussed. The context and structure of the cycling survey are described next. Analysis of the data begins with descriptions of the six cyclist types generated, before their choices in four risk-taking scenarios and their stated rationale are compared. Finally, targeted policies aimed

\footnotetext{
'School of Urban Planning, McGill University, Montreal, QC, Canada
}

Corresponding Author:

Address correspondence to Ahmed El-Geneidy:

ahmed.elgeneidy@mcgill.ca 
at increasing rule compliance by type are discussed, which are followed by the Conclusions section.

\section{Literature Review}

\section{Cyclist Typologies}

The generation of typologies is an effective research method used to understand variation in populations and to target policies toward them. One of the first typologies of cyclists was introduced in a study aiming to understand modern transport behavior in Norway (7). The study categorized cyclists according to why they choose to cycle rather than use public transport. "Cyclists of heart" choose the bicycle owing to their enjoyment of the ride; "cyclists of convenience" are drawn by the practicality of the mode; "cyclists of necessity" only choose to cycle in the absence of a better option. Though this typology is useful in understanding mode choice, it does not say much about differences in cyclist behavior or motivations.

Perhaps the most widespread cyclist typology hails from Portland, Oregon. The Portland typology was developed by a local transport planner, and is constructed from evaluations of cyclist confidence and comfort (8). The measure was used to categorize the entire city's commuting population, thus allowing local planners to attract non-cyclists to the mode with new infrastructure targeted to different cyclist types. The four types include "no way no how," "interested but concerned," "enthused and confident," and "strong and fearless." Though Geller's typology has become popular, his arbitrary creation of types that are then applied to the population can lead to incongruent labeling, such as identifying practicing cyclists as "no way no how" cyclists or non-cyclists as "strong and fearless" cyclists (9-11).

Another cyclist typology has been generated by Damant-Sirois, Grimsrud, and El-Geneidy (9), using multiple factors that lead to bicycle usage. Using data from a survey of Montreal cyclists, questions on cycling background, deterrents, and motivations as well as infrastructure preference and comfort were fed into a principal component analysis and used to generate k-means clusters. Four types were generated from seven factors: "dedicated cyclists," "path-using cyclists," "fairweather utilitarians," and "leisure cyclists." Whereas dedicated cyclists are comfortable traveling in almost all conditions, path-using cyclists require consistent and dedicated infrastructure. Fairweather utilitarians are multimodal and cycle only in ideal conditions, and leisure cyclists are looking for safe and fun recreational riding. The authors demonstrated how different policy interventions might be used to increase commuting frequency by bicycle, as each group has unique motivators and deterrents.
A final typology of note considers social perceptions and stereotypes of cyclists in generating a typology and compares the results between bicycle users and non-users (12). In this case, a principal components analysis was used to generate factors that themselves are considered types of cyclists. These types are "responsible bicyclists," "lifestyle bicyclists," "commuter bicyclists," and "hippygo-lucky bicyclists." Non-cyclists were more likely to consider the lifestyle bicyclist as a less responsible bicyclist when compared to their cycling counterparts. The authors note that overcoming the stereotypes of cyclists as a lifestyle group of extreme riders will be key in attracting non-cyclists to the mode and may help political efforts to improve safety conditions for cyclists. Though this study does not consider actual cyclist behavior, it demonstrates the importance of including cyclist risk-taking behaviors into account when generating a typology, to better counter negative public perceptions or stereotypes. All the above studies have shown the importance of generating cyclist typologies to develop public policy. It is also important to note that the differences in the cyclist typologies generated above mostly return to the type of questions posed to respondents.

\section{Cyclist Safety and Rule-Breaking}

Rule-breaking in the cycling literature has generally revolved around red-light running, perhaps owing to the violation being among the most infuriating to motorists. Finchham suggests that the negative opinions of cyclists can be traced to motorists feeling frustrated that cyclists are breaking laws that the motorists themselves cannot break, rather than the cyclists' behavior being a real danger to themselves or others (13). Understanding the different reasons why cyclists run red lights has thus become a popular research direction in that it may diffuse tensions around the violation while also identifying ways to reduce the practice.

Traffic camera observation is a popular method used to study red-light running behavior, allowing for a categorization of cyclists by appearance and action. Pai and Jou used the method in Taiwan, labeling the cyclists observed as "risk-taking," "opportunistic," and "lawobeying" (4). Though their estimation of demographic variables such as gender via traffic camera may be somewhat inaccurate, other significant findings concerning infrastructure type suggest that cyclists are more likely to run a red light on $\mathrm{T}$ or $\mathrm{Y}$ intersections, intersections with long light timers, and intersections of low traffic volume. A similar method undertaken by $\mathrm{Wu}$ et al. in China found $44 \%$ of observed cyclists were law-obeying, $31 \%$ risk-taking, and $25 \%$ opportunistic (14). This study concluded that as age and number of cyclists waiting for the light increased, the likelihood of running a red light 
decreased. Nevertheless, neither study can accurately discuss the demographic identities of their rule-breaking cyclist types based on traffic camera observation alone.

Although Johnson et al. also used the above method to track red-light running behavior in Australia (5), a second study by the same authors used a national online survey to better understand the practice (15). Two questions about red-light running were asked and six demographic variables were extracted. Around $37.3 \%$ of respondents who identified as cyclists reported running a red light previously, with gender, age, past collision involvement, and similar behavior while driving variables being significant in affecting the likelihood of running a red light in a binary logistic regression model. The most common reason for violation was to turn left on a red (Australia drives on the left), with the authors concluding that changes to local traffic rule should permit this maneuver for cyclists to minimize heavy truck collisions and increase cycling attractiveness.

Stated-preference surveys have also been used in Germany to understand cyclist rule violation and to increase rule compliance. Using two online surveys, Huemer examined the practice of riding the wrong way on cycling infrastructure and cycling without lights (16). A low perceived-risk of detection, high rationalization of the action, and young age increased the intention to cycle in the wrong direction, with every respondent having done so at least once. Most cyclists who violated the rule cited poor infrastructure for their action-being forced to take the wrong direction to reach their destinationwhile claiming to be disadvantaged in current traffic law and more comfortable because of their choice. Huemer argues for increasing cycling compliance through increased rule education and explanation of motorist expectations, matched with enforcement (16).

What most of the above studies have not included is an understanding of the rationalization of rule-breaking. Though Johnson et al. (15) use rationale to recommend policy changes, Huemer (16) on the other hand disregards rationale to argue for increased compliance. A final study aimed to contextualize rule-breaking through comparisons with motorists, suggesting that cyclists make rational decisions to contravene the law and are not reckless in doing so in the vast majority of cases (6). Cyclists were grouped by the level of risk taken in their responses to a set of scenarios, with relatively few cyclists categorized either as law abiders or undertaking reckless endangerment. The number one reason for cyclists breaking a law was personal safety, whereas saving time was chosen first by drivers and pedestrians. The rationalization of rule-breaking continues to be assigned to cyclists at large, meaning that any proposed response to violation (be it enforcement, infrastructure provision, or policy change) may continue to miss the mark in addressing specific behaviors present in specific cycling types. The introduction of cyclist typologies to the rule-breaking literature will allow for more fine-grained analysis based on the responses of cyclists themselves, rather than on passive observations or arbitrary categorization.

\section{Study Context}

Montreal is Canada's second-largest urban region, with a population of almost 4.1 million as of the 2016 Canadian Census (17). Around $29.5 \%$ of the region commutes to work using a sustainable mode: public transport, walking, or cycling. These numbers rise to $49 \%$ in the city itself, where public transport and cycling networks are more established. Considered among North America's most bikeable cities, Montreal's reputation has been sliding in one popular ranking. The Copenhagenize Index, which ranked Montreal 8th in 2011, listed the city as 20th in 2017 and noted that many areas remain too unsafe as infrastructure growth has been stagnant (18).

A notable change in the Montreal cycling environment was a revision of the local traffic laws, which has notably allowed for the implementation of vélorues (dedicated cycling streets), the elimination of demerit points for cyclists, and for cyclists to advance through pedestrian lights (19). The changes have also dramatically increased fines to cyclists and continue to enforce full stops at stop signs and before advancing through pedestrian signals. Overall, the rules of the road applying to cyclists remain generally identical to those that apply to motorists in Montreal, similar to many North American cities.

\section{Data}

Data from the 2018 Montreal Cycling Survey were used in this study to generate a typology of cyclists. The survey was available online from May 15th to June 15th, 2018 in both French and English. The survey was shared with the Transportation Research at McGill research group mailing list (roughly three thousand emails) as well as the group's social media. Links to the survey were shared by McGill University and several local cycling advocacy organizations, as well as Montreal's local sustainable commuting institute, Centre de gestion des déplacements de la région de Montréal. The survey was shared during a live television interview with CTV News Montreal, and several other local media outlets were contacted. Lastly, flyers were distributed to cyclists along bicycle lanes and on parking stands in downtown Montreal to ensure diversity in the recruitment process. Although these strategies improve the range of the convenience sampling approach, our final sample is not fully representative of the Montreal cycling population. 
At the end of the survey, 1,391 complete responses were collected, including current, lapsed, and noncyclists. Lapsed and non-cyclists were asked several questions as to why they chose not to cycle, as well as preferences for infrastructure that would attract them to riding. For this study, only active cyclists were included, resulting in a total of 1,329 respondents.

For active cyclists, the survey consisted of 10 sections: general information, cycling behavior, mobility spending, BIXI (Montreal's bicycle sharing system) usage, winter riding, cycling risk, cycling scenarios, local Montreal infrastructure, cycling history, and personal profile. These sections ask respondents to share their experiences cycling, including their frequency, motivations, deterrents, history, and demographic characteristics.

The cycling risk and cycling scenario sections were modeled after Marshall et al.'s survey design (6), with the first section asking respondents to rate their level of confidence with several aspects of cycling and their attitude toward risk. Though this approach relies on respondents' self-reporting their attitudes and behaviors, it allows for the capturing of their perceptions toward safety and risk. The cycling scenario section consists of four unique multiple-choice questions, all with a brief description and accompanying picture. The respondent is asked to choose between four reactions, one of which follows the Highway Safety Code and three of which do not in increasing levels of riskiness. Respondents who choose an illegal option must provide their rationale for doing so, with potential answers again reflecting Marshall et al.'s design (6). All four scenarios and their accompanying reaction choices can be seen in Figure 1.

\section{Analysis}

\section{Factor Analysis}

Several variables representing cycling deterrents, motivations, history, risk, and frequency were loaded into a factor analysis. The analysis was run several times as variables with low correlation to any factors (between -0.4 and 0.4 ) were removed. Scree plots were consulted to select the most appropriate number of factors for analysis, while being guided with the Eigen values. The resulting factors draw from questions on cycling motivations and cycling risk, see Table 1 for details.

The first factor, fearfulness, captures respondents' concerns about being involved and injured in a cycling collision. The second factor, efficiency-seeking, groups motivational variables in relation to the speed and efficiency of cycling. The third, confidence, captures cycling ability in both practical and theoretical skills. The fourth factor, lawfulness, includes past behavior toward the Highway Safety Code and the use of signals, with signals being included despite a lower correlation value because of its high topical relation. Lastly, health-seeking describes the motivational variables for cycling that revolve around personal and social wellness.

\section{Cyclist Typology}

Similarly to Damant-Sirois, the typology built here considered multiple dimensions and allowed the responses of cyclists to characterize themselves (9). Each cyclist was defined individually, rather than creating a label to assign cyclist by cyclist. The results of the principal component factor analysis were used in a k-means cluster analysis, with the analysis tried for three to seven groups. In our case, six clusters gave the best results; these six clusters are safety-first cyclists, unfamiliar cyclists, recreational cyclists, radical cyclists, risk-taking cyclists, and shortcut cyclists. The characteristics of each can be seen in Figure 2 , with additional comparisons visible in group means of selected variables in Table 2 .

\section{Safety-First Cyclists}

Safety-first cyclists ( $20 \%$ of sample) are strongly defined by their following of existing road rules and signals. They are among the most fearful while cycling, with neutral confidence in their abilities. Motivated more by efficiency than health, this type puts the law first when cycling.

\section{Unfamiliar Cyclists}

Unfamiliar cyclists $(12 \%$ of sample) are the newest cyclists with the least amount of experience. They have the largest proportion of students of any group. With very little confidence in their abilities and some fear, these cyclists also show low levels of lawfulness. Not motivated by efficiency or health, unfamiliar cyclists are most likely to not to cycle, and walk or transit instead.

\section{Recreational Cyclists}

Recreational cyclists (14\% of sample) are here to enjoy the ride; they could not care less about efficiency and are less fearful on their rides. This group uses their bicycles the least, preferring to drive for utilitarian trips. They are the oldest group and have the highest proportion of retirees.

\section{Radical Cyclists}

Radical cyclists ( $23 \%$ of sample) are the cycling devout; they complete the most utilitarian trips by bike of all groups, including through winter, and are least likely to find a reason not to cycle. They are the youngest, most fearful, and least lawful group; radical cyclists are sold on the health and efficiency benefits of cycling, having 


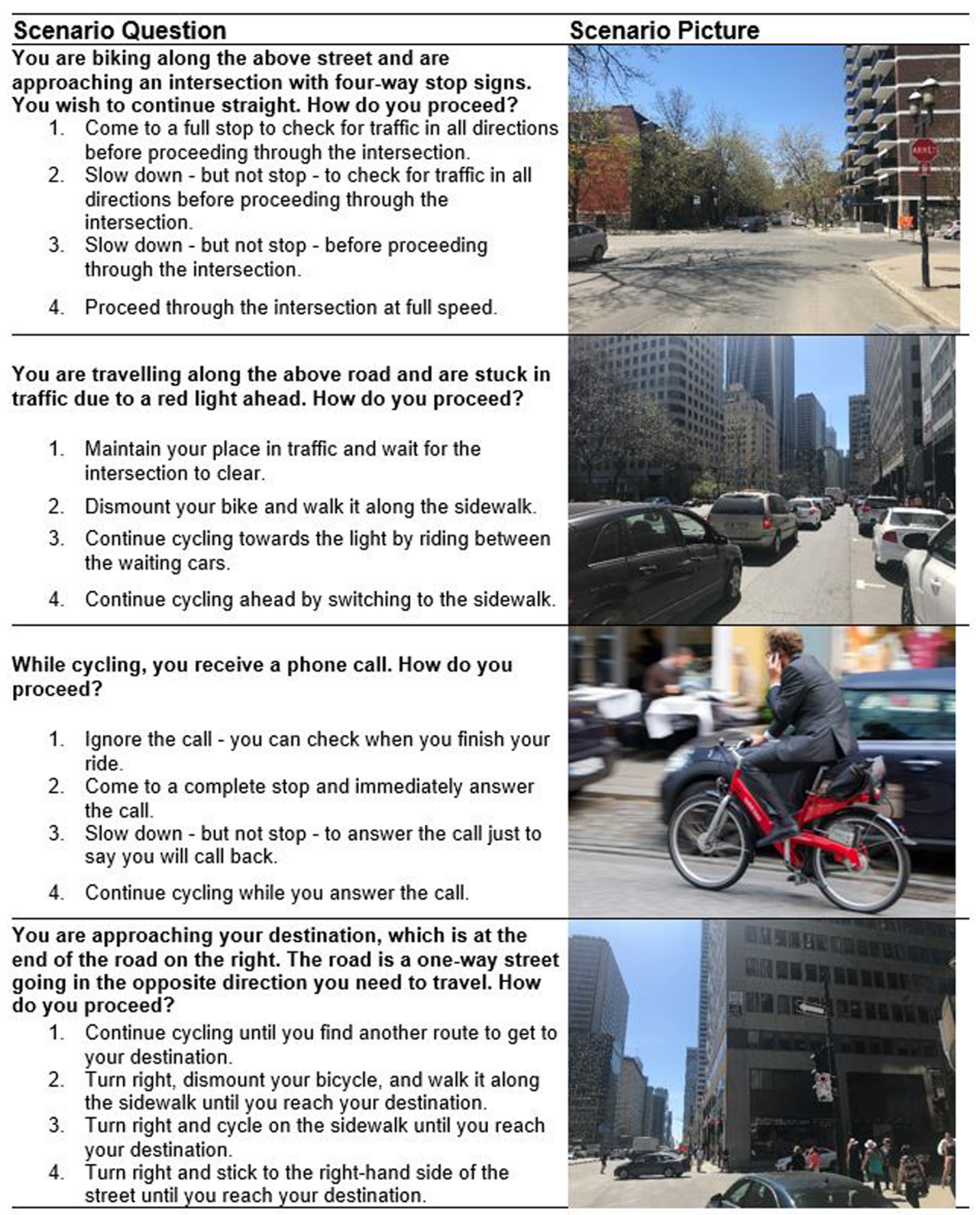

Figure I. Scenario design and responses, from Montreal Cycling Survey 2018.

rejected car usage and taken a hard line in claiming rightof-way against the car.

\section{Risk-Taking Cyclists}

Risk-taking cyclists ( $10 \%$ of sample) do not worry about their health; confident in their abilities, they do not consider themselves lawful. Risk-taking cyclists are most likely to use a BIXI.

\section{Shortcut Cyclists}

Shortcut cyclists (22\% of sample) are the last group, defined by their complete lack of fearfulness. They are more confident and less lawful than the average cyclist.
Shortcut cyclists have the shortest commutes of all and the most cycling experience. Familiar and at ease on their routes, shortcut cyclists are somewhat motivated by health and efficiency considerations.

\section{Scenario Responses}

Having generated a cyclist typology, responses to the four scenarios can be compared. Figure 3 shows each cyclist type according to the percentage of responses that follow the Quebec Highway Safety Code (Option 1 for each scenario in Figure 1). Very few respondents followed the code in all scenarios; less than $2 \%$ of safetyfirst cyclists, unfamiliar cyclists, and recreational cyclists chose rule-abiding answers (see Figure 3). At the other 
Table I. Factors, Variables, and Loadings

Fearfulness

How worried are you of potentially being injured in a cycling collision?

How worried are you of potentially being involved in a cycling collision?

Efficiency-seeking

How important is taking the fastest way from A to B in your decision to cycle now? 0.804

How important is predictability of travel time in your decision to cycle now? $0.76 \mathrm{I}$

How important is the low cost of cycling in your decision to cycle now?

Confidence

How confident are you in your cycling ability?

How confident are you in your knowledge of cycling rules, according to the Quebec Highway Safety Code?

Lawfulness

Thinking of my typical behavior in the past year, I always follow the Quebec Highway Safety Code while cycling. 0.823

Thinking of my typical behavior in the past year, I use signals for all of my movements while cycling. 0.435

Health-seeking

How important are environmental reasons in your decision to cycle now? 0.74

How important are health reasons in your decision to cycle now?

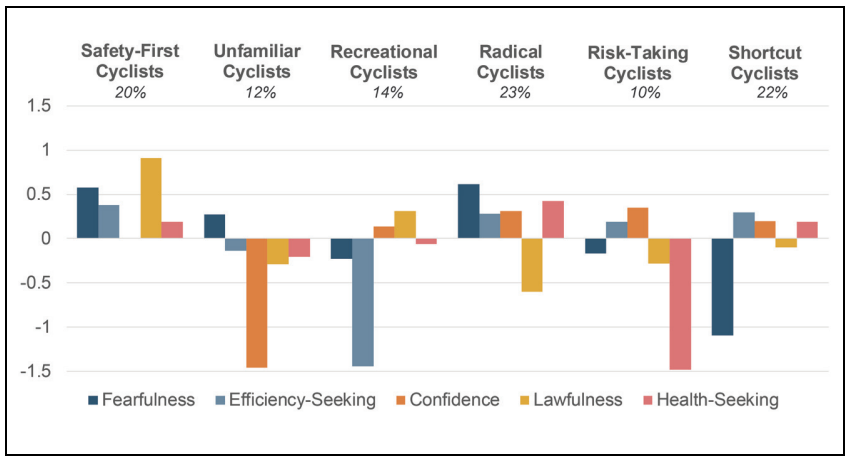

Figure 2. Cyclist types.

Note: Percentages may not add to $100 \%$ due to rounding. end of the scale are those who did not choose a single response following the code, ranging from $16.5 \%$ to $25.3 \%$ of each type. In order of most to least rule-breaking, the types are radical cyclists (who all broke the code at least twice), risk-taking cyclists, shortcut cyclists, safety-first cyclists, and recreational cyclists.

Breaking the responses down by scenario, the picture of rule-breaking shifts away from universal disregard for the Highway Safety Code. It becomes clear that all types commonly break certain rules and consistently follow others. Table 3 provides statistics for each scenario by cyclist type.

Table 2. Selected Demographic Characteristics of Cyclist Types

\begin{tabular}{|c|c|c|c|c|c|c|}
\hline Demographic & $\begin{array}{l}\text { Safety-first } \\
\text { cyclists }\end{array}$ & $\begin{array}{l}\text { Unfamiliar } \\
\text { cyclists }\end{array}$ & $\begin{array}{l}\text { Recreational } \\
\text { cyclists }\end{array}$ & $\begin{array}{l}\text { Radical } \\
\text { cyclists }\end{array}$ & $\begin{array}{l}\text { Risk-taking } \\
\text { cyclists }\end{array}$ & $\begin{array}{l}\text { Shortcut } \\
\text { cyclists }\end{array}$ \\
\hline Age (years) & 42.4 & 41.0 & 50.2 & 40.3 & 43.4 & 43.1 \\
\hline Cycling experience (years) & 16.3 & 13.0 & 17.5 & 17.2 & 18.0 & 20.2 \\
\hline$\%$ female, non-binary, or other & 0.51 & 0.73 & 0.30 & 0.35 & 0.27 & 0.37 \\
\hline$\%$ student & 0.08 & 0.25 & 0.05 & 0.12 & 0.10 & 0.11 \\
\hline$\%$ retired & 0.07 & 0.06 & 0.22 & 0.04 & 0.06 & 0.07 \\
\hline \multicolumn{7}{|l|}{ Trip behavior } \\
\hline Commute distance $(\mathrm{km})$ & 6.71 & 7.02 & 6.80 & 6.07 & 6.72 & 5.67 \\
\hline \# of weekly work trips by bicycle & 4.77 & 2.83 & 2.65 & 4.88 & 4.06 & 3.93 \\
\hline \# of weekly grocery trips by bicycle & 1.00 & 1.01 & 0.56 & 1.36 & 1.10 & 1.07 \\
\hline \# of weekly leisure trips by bicycle & 2.42 & 2.28 & 1.60 & 2.87 & 2.61 & 2.29 \\
\hline $\begin{array}{l}\% \text { who cycle in winter } \\
\text { Mode behavior }\end{array}$ & 0.27 & 0.14 & 0.14 & 0.43 & 0.36 & 0.37 \\
\hline$\%$ who when not cycling, drive & 0.25 & 0.23 & 0.43 & 0.23 & 0.26 & 0.25 \\
\hline $\begin{array}{l}\% \text { who when not cycling, take } \\
\text { public transport }\end{array}$ & 0.76 & 0.82 & 0.61 & 0.73 & 0.74 & 0.73 \\
\hline$\%$ who when not cycling, walk & 0.42 & 0.56 & 0.34 & 0.39 & 0.42 & 0.41 \\
\hline$\%$ who use BIXI & 0.40 & 0.46 & 0.22 & 0.44 & 0.55 & 0.38 \\
\hline $\begin{array}{l}\% \text { agree, cyclists should always } \\
\text { have the right-of-way }\end{array}$ & 0.54 & 0.58 & 0.49 & 0.69 & 0.51 & 0.55 \\
\hline
\end{tabular}




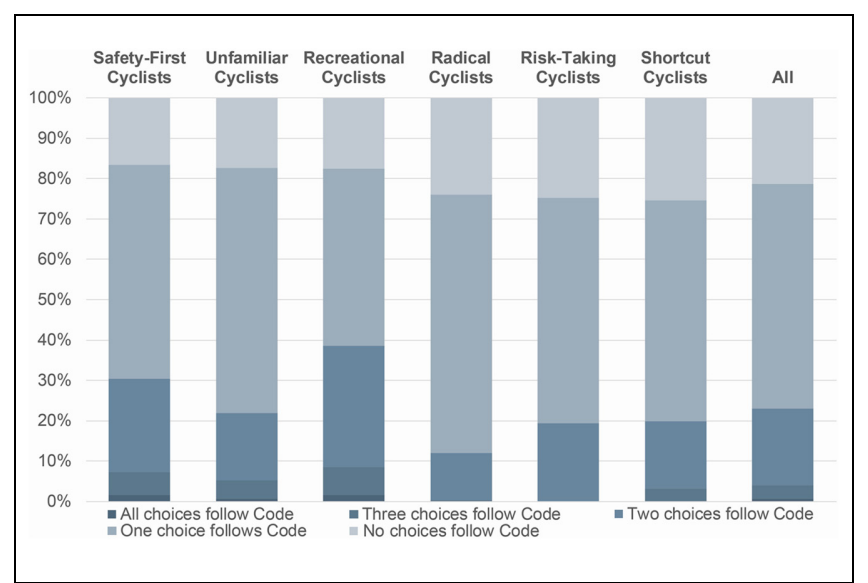

Figure 3. Scenario response by cyclist type.

A high level of consensus between types suggests a unique approach to rules shared by all cyclists. The consensus against following the code in scenarios 1, 2, and 4 suggests that some rules shared with motorists are not considered rational by even the most law-abiding cycling types. Similarly, the consensus for following the code in reference to phone use across all types suggests that the rationale for this rule is accepted by even the least lawabiding cycling types. Within this consensus remains room for variation: for example, although most cyclists in each type choose Option 2 in Scenario 1 (choosing to slow, but not stop, before passing through a stop sign), safety-first cyclists and recreational cyclists show a high level of variation from the majority. These variations may be attributed to the unique characteristics of each cyclist type (fearfulness, confidence, lawfulness, efficiency motivations, and health motivations).
An analysis of variance (ANOVA) conducted on scenario responses (shown in Table 4) found that the differences are significant in scenarios 1,2 , and 4 , though not in scenario 3 . This scenario, on cellphone usage, is the only one in which all answer statistically similarly, whereas the other three scenarios show significant differences in the behavioral reactions of each type.

\section{Scenario Rationale}

For those who did not follow the Highway Safety Code in their responses, a follow-up question appeared asking them to state the rationale for not following the rule. Respondents could select only one rationale, with most of the "other" open text option being used to select multiple responses. The responses can be seen in Figure 4, broken down by cyclist type. Unsurprisingly, safety-first cyclists were most concerned with their safety when choosing to break the law, with $43.3 \%$ choosing "it was the safest option" or "it made sure I was visible to cars." Similarly, radical cyclists were most concerned with saving time or energy, reflecting the high efficiencymotivation they have to cycle. Risk-taking and radical cyclists are most likely to have a respondent choose rulebreaking for fun or for protest, but these numbers are very low at $3.2 \%$ and $2.7 \%$ respectively.

When observing the rationales given, what is most evident is the relative similarity between all cyclist types despite the discrepancies in their cycling attitude and behavior. Efficiency concerns are more important than safety concerns for all types except safety-first cyclists but are not significantly more often chosen amongst other types. No single cyclist type is claiming one rationale more than another in rule-breaking; rather, rule-

Table 3. Scenario Response by Cyclist Type

\begin{tabular}{|c|c|c|c|c|c|c|c|}
\hline & $\begin{array}{l}\text { Level } \\
\text { of risk }\end{array}$ & $\begin{array}{l}\text { Safety-first } \\
\text { cyclists }\end{array}$ & $\begin{array}{l}\text { Unfamiliar } \\
\text { cyclists }\end{array}$ & $\begin{array}{l}\text { Recreational } \\
\text { cyclists }\end{array}$ & $\begin{array}{l}\text { Radical } \\
\text { cyclists }\end{array}$ & $\begin{array}{l}\text { Risk-taking } \\
\text { cyclists }\end{array}$ & $\begin{array}{l}\text { Shortcut } \\
\text { cyclists }\end{array}$ \\
\hline \multirow[t]{4}{*}{ Scenario I } & I & $16 \%$ & $10 \%$ & $15 \%$ & $1 \%$ & $4 \%$ & $9 \%$ \\
\hline & 2 & $82 \%$ & $85 \%$ & $79 \%$ & $95 \%$ & $91 \%$ & $86 \%$ \\
\hline & 3 & $2 \%$ & $3 \%$ & $5 \%$ & $3 \%$ & $4 \%$ & $4 \%$ \\
\hline & 4 & $0 \%$ & $1 \%$ & $1 \%$ & $1 \%$ & $1 \%$ & $1 \%$ \\
\hline \multirow[t]{4}{*}{ Scenario 2} & I & $11 \%$ & $7 \%$ & $13 \%$ & $4 \%$ & $8 \%$ & $6 \%$ \\
\hline & 2 & $9 \%$ & $8 \%$ & $8 \%$ & $3 \%$ & $4 \%$ & $3 \%$ \\
\hline & 3 & $78 \%$ & $81 \%$ & $78 \%$ & $92 \%$ & $87 \%$ & $90 \%$ \\
\hline & 4 & $2 \%$ & $4 \%$ & $0 \%$ & $2 \%$ & $2 \%$ & $1 \%$ \\
\hline \multirow[t]{4}{*}{ Scenario 3} & 1 & $75 \%$ & $79 \%$ & $75 \%$ & $71 \%$ & $68 \%$ & $69 \%$ \\
\hline & 2 & $25 \%$ & $17 \%$ & $23 \%$ & $25 \%$ & $29 \%$ & $27 \%$ \\
\hline & 3 & $0 \%$ & $1 \%$ & $1 \%$ & $1 \%$ & $2 \%$ & $1 \%$ \\
\hline & 4 & $1 \%$ & $3 \%$ & $1 \%$ & $2 \%$ & $1 \%$ & $2 \%$ \\
\hline \multirow[t]{4}{*}{ Scenario 4} & I & $21 \%$ & $14 \%$ & $28 \%$ & $12 \%$ & $15 \%$ & $13 \%$ \\
\hline & 2 & $53 \%$ & $41 \%$ & $40 \%$ & $34 \%$ & $38 \%$ & $37 \%$ \\
\hline & 3 & $10 \%$ & $15 \%$ & $10 \%$ & $16 \%$ & $9 \%$ & $13 \%$ \\
\hline & 4 & $16 \%$ & $30 \%$ & $22 \%$ & $39 \%$ & $38 \%$ & $37 \%$ \\
\hline
\end{tabular}


Table 4. ANOVA Tests by Scenario

\begin{tabular}{|c|c|c|c|c|c|c|c|}
\hline & Source of variation & SS & $d f$ & MS & $F$ & $p$-value & F crit \\
\hline \multirow[t]{3}{*}{ Scenario I } & Between groups & 4.867 & 5.000 & 0.973 & \multirow[t]{3}{*}{6.655} & \multirow[t]{3}{*}{0.000} & \multirow[t]{3}{*}{2.221} \\
\hline & Within groups & 193.514 & 1323.000 & 0.146 & & & \\
\hline & Total & $|98.38|$ & 1328.000 & & & & \\
\hline \multirow[t]{3}{*}{ Scenario 2} & Between groups & 12.014 & 5.000 & 2.403 & \multirow[t]{3}{*}{7.098} & \multirow[t]{3}{*}{0.000} & \multirow[t]{3}{*}{2.221} \\
\hline & Within groups & 447.900 & 1323.000 & 0.339 & & & \\
\hline & Scenario 3 & 459.914 & 1328.000 & & & & \\
\hline \multirow[t]{3}{*}{ Scenario 3} & Between groups & 1.931 & 5.000 & 0.386 & \multirow[t]{3}{*}{1.170} & \multirow[t]{3}{*}{0.321} & \multirow[t]{3}{*}{2.221} \\
\hline & Within groups & 436.598 & 1323.000 & 0.330 & & & \\
\hline & Total & 438.530 & 1328.000 & & & & \\
\hline \multirow[t]{3}{*}{ Scenario 4} & Between groups & 78.605 & 5.000 & $|5.72|$ & \multirow[t]{3}{*}{13.830} & \multirow[t]{3}{*}{0.000} & \multirow[t]{3}{*}{2.221} \\
\hline & Within groups & 1503.884 & 1323.000 & 1.137 & & & \\
\hline & Total & 1582.489 & 1328.000 & & & & \\
\hline
\end{tabular}

Note: $\mathrm{SS}=$ sum of the squares of data; $\mathrm{df}=$ degrees of freedom; $M S=$ mean sum of the squares of data; $F=f$-statistic.

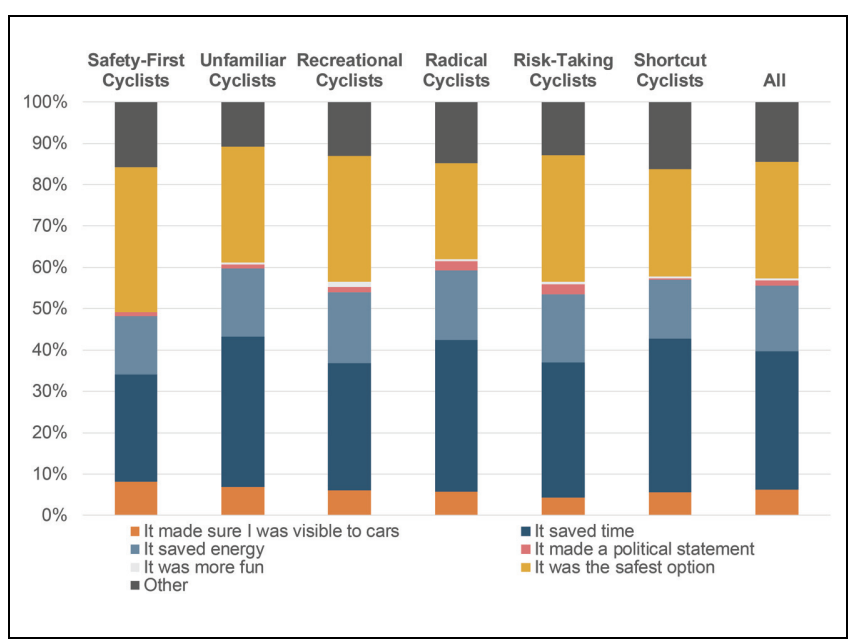

Figure 4. Rationale for not following the Highway Safety Code by cyclist type.

breaking is a decision that is similarly rationalized by all types of cyclists.

When considering the given rationale by rule-breakers of all cyclist types by scenario, it is clear that each scenario has a predominant concern. Figure 5 shows the percentage of all cyclists selecting a given rationale for each scenario. In Scenario 1, cyclists choose to break the rules and not come to a complete stop to save energy, whereas in Scenario 2 cyclists choose not to wait with traffic to save time. In Scenario 3, cyclists who chose to stop immediately to answer a call perceive this as the safest option. Only Scenario 4 sees a roughly equal split in the dominant rationale, with cyclists divided on saving time and seeking safety. This reflects the division in the "appropriate" choice of rule-breaking, with respondents split between walking the bike up the sidewalk and continuing to ride their bike against traffic

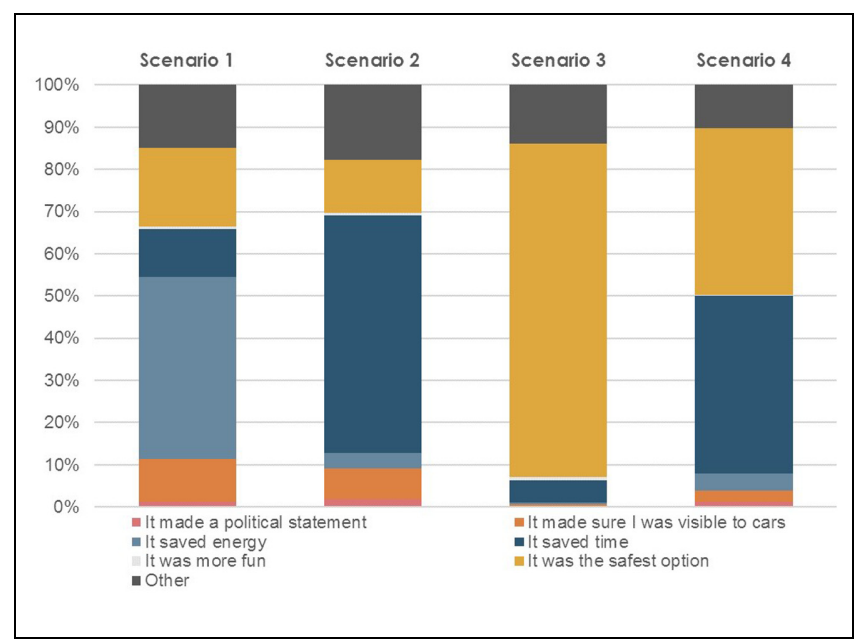

Figure 5. Rationale for not following the Highway Safety Code by scenario.

\section{Discussion}

With most cyclists choosing not to follow traffic laws to some extent, it is clear that frequent revision of the rules must be a key plank of cycling policy. These revisions should take into consideration the primary rationale for rule-breaking in each scenario; for example, the desire to save energy should be factored into stop sign rules for cyclists. With or without revisions, however, there will always be a percentage of cyclists who choose not to follow the law. These riders require unique and targeted policies based on their cyclist type if they are to make a sustainable change to rule-abiding behavior.

Our cyclist typology identified unique characteristics between groups that may be used to develop targeted policies for increasing rule compliance. By addressing these characteristics, rule-breaking behavior could be reduced. Figure 6 displays the orientation of cycling types to four 


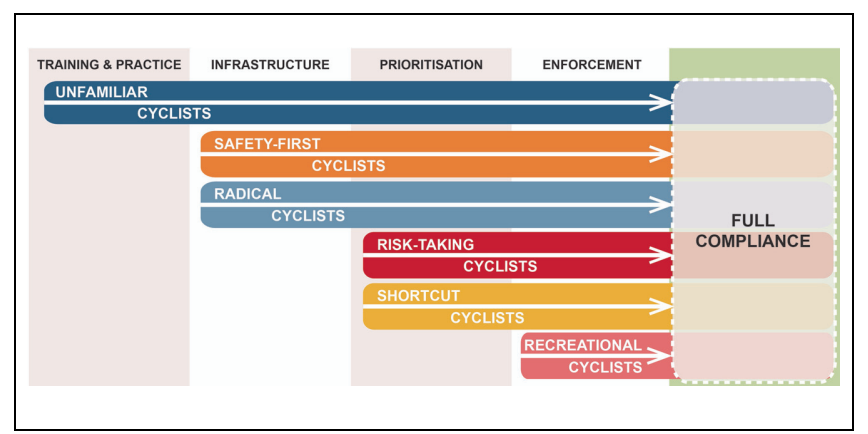

Figure 6. Targeting cycling policies for increasing rule compliance by cyclist type.

recommended policy interventions, in the aim of achieving the highest level of compliance possible by all cyclists. Each policy recommendation corresponds to a shared characteristic of the present cyclist types: training and practice targets low confidence, infrastructure targets high fearfulness, and prioritization targets high efficiency-seeking. Please note that the size of each bar does not correspond to the percentage of rule-breakers present in each type, for example, unfamiliar cyclists are not most in need of intervention to assure rule compliance. Rather, the size of the bar only corresponds to which policies could affect members of a cyclist type.

Increasing cycling rule compliance begins with establishing confidence, namely affecting unfamiliar cyclists. This begins with childhood education, a policy that has been piloted in Montreal (20) and in other parts of the world $(21,22)$. Such education might include practical training and education of cycling rules, both lacking amongst unfamiliar cyclists.

Providing clear and legible infrastructure is key in countering fearfulness, affecting unfamiliar cyclists, safety-first cyclists, and radical cyclists. These types share a high level of fear of being involved in a collision while cycling. Reducing this fear necessitates a comprehensive grid of dedicated cycling infrastructure, making it easy to follow the rules in an environment with minimal exposure to other modes of transport. Particular attention should be paid to intersections, with clear communication of expected cyclist behavior through their design.

Emphasizing the efficiency benefits of cycling affects most cycling types and can be promoted through cycling prioritization in planning and policy. Providing synchronized signal corridors is one example of formalizing the efficiency of cyclists and minimizing the need to break a rule. Unfamiliar cyclists, safety-first cyclists, radical cyclists, risk-taking cyclists, and shortcut cyclists will most appreciate improvements to their trip efficiency and may no longer need to break a rule as a result.

There will always be some need for continued enforcement, as radical cyclists, risk-taking cyclists, and shortcut cyclists will not necessarily conform to rules as easily as recreational cyclists and safety-first cyclists will. The proposed policies should be paired with regular revision to traffic laws to accommodate cyclists if they are to be of maximum effectiveness.

These policies may also be applied in other regions with similar cycling experiences as Montreal. Although the cycling cultures of different regions may have different approaches to rule-breaking, the same cyclist types are expected to be present in varying proportions.

\section{Conclusions}

This study generated a unique cycling typology that includes rule-breaking in its categorization, allowing for a cyclist-by-cyclist understanding of how and why rules are broken. Uniquely defined by their motivations to cycle, fearfulness, confidence, and lawfulness, all six cyclist types were in agreement when breaking the rules. The similar approach to rule-breaking taken by all cyclist types reveals the impracticality of traffic laws that do not consider the unique mode of cycling in enforcing safety. Actions labeled as careless and dangerous by other road users are in fact considered the safest and most rational by cyclists themselves, across all types, yet infrastructure and policy remain disconnected from this reality.

Addressing this disconnect requires a reconsideration of traffic law and the potential creation of bicyclespecific rules for the road. Bicycle-specific rules may be a worthwhile option for regions with high levels of rulebreaking, as they can consider the rationale and safety of the mode specifically. Even with traffic law changes, however, some cyclists will continue to break the rules. Increasing rule compliance requires a targeted approach to enforcement, as no one-size-fits-all approach exists for all cyclist types. Though a change in the law is enough for some cyclists to change their behavior, others may only respond to infrastructure changes, further training and education, or cycling prioritization.

Our findings are limited by the convenience sampling approach and self-reported nature of the survey design. Future research could adopt a more representative sample approach to verify the cyclist types generated here. Addressing the self-reported nature of respondents' behaviors and rationales could involve using direct observation, though participants may change their behaviors in this environment.

Transport planners, policy makers, and law enforcement should note the diversity of cycling types when rethinking cycling strategies and laws for their region. Any reconsideration of cycling policy, infrastructure, or laws must consider the actions and behaviors of the cyclists on the street as rational choices aimed at maximizing safety and efficiency, rather than the actions of a reckless few. 


\section{Acknowledgments}

This research was funded in part by the Social Sciences and Humanities Research Council of Canada and Natural Sciences and Engineering Research Council of Canada. Technical support for the survey was provided by Daniel Schwartz of xxx, for which the authors are very grateful. We thank Vélo-Quebec, Montreal Bike Coalition, the CGD de Montreal, and the McGill Reporter for their collaboration in disseminating our survey. Thank you to all Transportation Research at McGill research members for their support and guidance during the design, analysis, and writing process.

\section{Author Contributions}

The authors confirm contribution to the paper as follows: study conception and design: NC, AE-G; data collection: NC, AE-G; analysis and interpretation of results NC, AE-G; draft manuscript preparation: NC, AE-G. Both authors reviewed the results and approved the final version of the manuscript.

\section{References}

1. Damian Smith, C., and J. Levin. It's Anarchy in the Streets of Toronto for Cyclists. NOW, 2018.

2. Olson, I. Cyclist Death Sparks Renewed Call for Crackdown on Montreal Truck Traffic. CBC News, 2018.

3. Kurl, S., and I. Holliday. Bike Lane Divide: Canadians More Likely to Blame Cyclists than Drivers for Conflict on the Road. Angus Reid Institute, 2018.

4. Pai, C., and R. Jou. Cyclists' Red-Light Running Behaviours: An Examination of Risk-Taking, Opportunistic, and Law-Obeying Behaviours. Accident Analysis and Prevention, Vol. 62, No. 1, 2014, pp. 191-198.

5. Johnson, M., S. Newstead, J. Charlton, and J. Oxley. Riding through Red Lights: The Rate, Characteristics and Risk Factors of Non-Compliant Urban Commuter Cyclists. Accident Analysis and Prevention, Vol. 43, No. 1, 2011, pp. 323-328.

6. Marshall, W. E., D. Piatkowski, and A. Johnson. Scofflaw Bicycling: Illegal but Rational. Journal of Transport and Land Use, Vol. 10, No. 1, 2017.

7. Jensen, M. Passion and Heart in Transport - A Sociological Analysis on Transport Behaviour. Transport Policy, Vol. 6, 1999, pp. 19-33.

8. Geller, R. Four Types of Cyclists. City of Portland Office of transportation, 2006.

9. Damant-Sirois, G., M. Grimsrud, and A. El-Geneidy. What's your Type: A Multidimensional Cyclist Typology. Transportation, Vol. 41, No. 6, 2014, pp. 1153-1169.
10. Dill, J., and N. McNeil. Four Types of Cyclists? Examination of Typology for Better Understanding of Bicycling Behavior and Potential. Transportation Research Record: Journal of the Transportation Research Board, 2013. 2387: 129-138.

11. Dill, J., and N. McNeil. Revisiting the Four Types of Cyclists. Findings from a National Survey. Transportation Research Record: Journal of the Transportation Research Board, 2016. 2587: 90-99.

12. Gatersleben, B., and H. Haddad. Who is the Typical Bicyclist? Transportation Research Part F: Traffic Psychology and Behaviour, Vol. 13, No. 1, 2010, pp. 41-48.

13. Fincham, B. Bicycle Messengers and the Road to Freedom. The Sociological Review, Vol. 54, No. 1, 2006, pp. 208-222.

14. Wu, C., L. Yao, and K. Zhang. The Red-Light Running Behaviour of Electric Bike Riders and Cyclists at Urban Intersections in China: An Observational Study. Accident Analysis and Prevention, Vol. 49, No. 11, 2012, pp. 186-192.

15. Johnson, M., J. Charlton, J. Oxley, and S. Newstead. Why do Cyclists Infringe at Red Lights? An Investigation of Australian Cyclists' Reasons for Red Light Infringement. Accident Analysis and Prevention, Vol. 50, No. 1, 2013, pp. 840-847.

16. Huemer, A. Motivating and Deterring Factors for Two Common Traffic-Rule Violations of Cyclists in Germany. Transportation Research Part F: Traffic Psychology and Behaviour, Vol. 54, 2018, pp. 223-235.

17. Statistics Canada. Canadian Census. 2016.

18. Copenhagenize Design Co. The Copenhagenize Index 2017: Bicycle Friendly Cities. 2017.

19. New Highway Safety Code Measures. Gouvernement du Quebec. https://www.transports.gouv.qc.ca/en/code-securite-routiere/Pages/csr.aspx/. Accessed July 20, 2018.

20. van Lierop, D., M. Bebronne, and A. El-Geneidy. Bicycle Education for Children: Evaluation of a Program in Montreal. Transportation Research Record: Journal of the Transportation Research Board, 2016. 2587: 23-33.

21. Hooshmand, J., G. Hotz, V. Neilson, and L. Chandler. BikeSafe: Evaluating a Bicycle Safety Program for Middle School Aged Children. Accident Analysis \& Prevention, Vol. 66, 2014, pp. 182-186.

22. Lachapelle, U., R. Noland, and L. Von Hagen. Teaching Children about Bicycle Safety: An Evaluation of the New Jersey Bike School Program. Accident Analysis \& Prevention, Vol. 52, 2013, pp. 237-249.

The Standing Committee on Bicycle Transportation (ANF20) peer-reviewed this paper (19-00494). 